\title{
Manufacturing Zero-Cement Bricks by Replacing Cement with Recycled Aggregates and Blast Furnace Slag Powder
}

\author{
Park, Kyung-Taek Han, Cheon-Goo* Kim, Dae-Gun \\ Department of Architecture Engineering, Cheongju University, Sangdang-Gu, Cheong-Ju, 360-764, Korea
}

\begin{abstract}
In this study, a zero-cement brick is manufactured by replacing cement with recycled aggregates and blast furnace slag powder. Experimental tests were conducted with standard sized samples of $190 \times 57 \times 90 \mathrm{~mm}$ (KS F 4004), and this manufacturing technique was simulated in practice. Results showed that the zero-cement brick with $0.35 \mathrm{~W} / \mathrm{B}$ had the highest compressive strength, but the lowest absorption ratio. This absorption ratio of zero-cement brick with 0.35 W/B was lower than the required level determined by KS F 4004. Hence, to increase the absorption ratio, crushed fine aggregate (CA) and emulsified waste vegetable oil (EWO) were used in combination in the zero-cement brick. It was found that the zero-cement brick with CA of $20 \%$ and EWO of $1 \%$ had the optimum combination, in terms of having the optimum strength development $(12 \mathrm{MPa})$ and the optimum absorption ratio $(8.4 \%)$ that satisfies the level required by KS. In addition, it is demonstrated that for the manufacturing of zero-cement brick of 1000 , this technique reduces the manufacturing cost by $5 \%$ compared with conventional cement brick.
\end{abstract}

Keywords : blast furnace slag powder, recycled aggregates, zero cement, alkali activation, bricks

\section{Introduction}

In recent years, there has been a keen interest in zero-cement technologies that can minimize $\mathrm{CO}_{2}$ emission in the cement manufacturing process[1].

However, one of the zero-cement implementation technologies is the alkali activation technique that enables strength to be developed in mortar by mixing alkali activator and mineral binders, including blast furnace slag (hereinafter BS) and fly ash. The technologies developed thus far have had some problems in their application to actual construction sites, including increased material cost and risk during construction, and reaction of alkali

Received : August 14, 2012

Revision received : October 22, 2012

Accepted : October 23, 2012

* Corresponding author : Han, Cheon-Goo

[Tel: 82-43-229-8480, E-mail: cghan@cju.ac.kr]

(c) 2013 The Korea Institute of Building Construction, All rights reserved. aggregation due to more than 9 mols of strong alkali activator like $\mathrm{NaOH}$ and $\mathrm{KOH}[2,3]$.

On the other hand, BS, a byproduct generated in steel mill industry, has potential hydraulic reactivity, which means the strength is activated by an activator such as alkali or sulfate. For this reason, BS is not used separately but as a supplementary cementitious material within a limited range[4]. As the domestic production volume of BS has been greatly increased due to a new steel mill built in Dangjin, it is appropriate to consider expanding the utilization of the material.

In addition, recycled aggregate obtained from construction waste (hereinafter RA) is an alkali porous low-quality aggregate with cement mortar ingredient on the base matrix. It was designated for use as an aggregate for low-strength concrete with $21 \mathrm{MPa}$ or lower[5]. However, although it has the fundamental problem of potentially polluting soil and 
water quality in alkali, RA is mainly used for low-quality construction work, like road base or soil mounding and covering[6].

Therefore, a new study was conducted to provide a complementary solution to the aforementioned problems from a resource recycling perspective. That is, it was revealed that the alkali material coming out of RA activated the potential hydraulic reactivity of BS, and that the strength of the mortar was developed satisfactorily, even with no cement[7]. According to the research findings, it was effective in low-strength and lean mix compared to existing concrete, and for this reason, this research focuses on brick manufacture of secondary product[8].

Thus, a series of experiments were conducted to determine the practical applicability of zero cement bricks incorporating $\mathrm{BS}$ and $\mathrm{RA}$ on construction sites. The basic physical properties of the BS bricks were examined, and the absorption reduction plan was tested in a mock-up test and applied to an actual factory to manufacture effective zero cement bricks.

\section{Review of previous studies}

Figure 1 shows regression lines of compressive strength of general concrete and BS mortar with RA at 28 days depending on W/B.

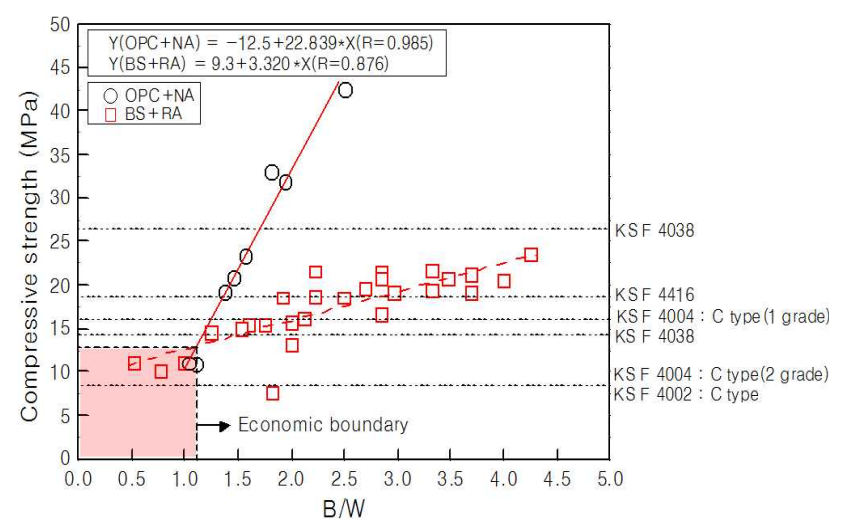

Figure 1. Linear regression of compressive strength depending on $\mathrm{B} / \mathrm{W}$ with general concrete and RA using the BS mortar
Overall, the general concrete made using ordinary Portland cement (hereinafter $\mathrm{OPC}$ ) showed a dramatic development of strength, while zero cement mortar with $\mathrm{BS}$ and RA showed a comparatively gentle development. Finally, based on the regression line between $\mathrm{b} / \mathrm{w}$ ratio and compressive strength, the optimal b/w ratio was derived for each criterion. For the strength of $15 \mathrm{MPa} 25 \mathrm{MPa}$, which is as high as that of general cement, 2.0-4.5 W/B was calculated when using $\mathrm{BS}$ and $\mathrm{RA}$, which is considered to not be economical, as 1.3-2.0 W/B was calculated when using $\mathrm{OPC}$ and natural fine aggregate (hereinafter NA).

However, for the strength of $8 \mathrm{MPa}$ and $15 \mathrm{MPa}$, required for a relatively low strength, it was shown effectively that the $\mathrm{b} / \mathrm{w}$ ratio was calculated at around 1.0 when using $\mathrm{OPC}$ and NA, while it was around 0.5 when using BS and RA. BS and RA were verified to be more economically feasible for lean mix.

Therefore, when using BS and RA, of the secondary products stipulated in KS, the KS F 4004 C Type 2 Grade brick is most appropriate for this study.

\section{Experiment plan and method}

\subsection{Experiment plan}

The experiment in this research can be largely divided into Series I and II, as shown in Table 1. That is, in Series I the basic physical properties of bricks with RA and BS (change of W/B) were examined, and in Series II absorption was tested for reduction \{crushed fine aggregate $(\mathrm{CA})+$ emulsified waste oil(EWO)\}. The mix proportion of mortar for Series I and II is shown in Tables 2 and 3 , respectively.

First, the mix proportion of mortar for brick production in Series I and II was set at 1:10 considering the mix proportion used in an actual 
brick factory. In Series I, W/B was set at five different levels: 25, 30, 35, 40, and 45\%. In addition, in Series II, W/B was set at $35 \%$, and the replacement rate of $\mathrm{CA}$ was set at five different levels: 0, 10, 20, 30, and 40\% while the replacement rate of EWO was set at 4 different levels: 0, 1, 2, and 3\%. Respective levels of CA and EWO were combined to test 20 different levels, and 25 different types of specimens were tested in this research.

All bricks were cured with steam considering the factory conditions, and the compressive strength and absorption of the bricks were measured in the quality tests.

Table 1. Experimental plan

\begin{tabular}{|c|c|c|}
\hline & Factors & Levels \\
\hline Series 1 & $\begin{array}{c}\text { Mix proportion (BS:RA) } \\
\text { W/B (\%) }\end{array}$ & $\begin{array}{l}\cdot 1: 10 \\
\cdot 25,30,35,40,45\end{array}$ \\
\hline \multirow{4}{*}{ Series II } & $\begin{array}{c}\text { Mix proportion (BS:RA) } \\
\text { W/B (\%) }\end{array}$ & $\begin{array}{l}1: 10 \\
35\end{array}$ \\
\hline & $\begin{array}{c}\text { Combined } \\
\text { replacement }\end{array}$ & $\begin{array}{l}0,10,20,30,40 \\
0,1,2,3\end{array}$ \\
\hline & Curing method & - Steam curing $\left(65^{\circ} \mathrm{C}\right)$ \\
\hline & Experiment & $\begin{array}{l}\text { Compressive strength } \\
\text { ( } 3,7 \text { days) } \\
\text { - Water Absorption ( } 7 \text { days) }\end{array}$ \\
\hline
\end{tabular}

1) $\mathrm{CA}:$ Crushed fine aggregates

2) EWO : Emulsified waste vegetable oil

\subsection{Test materials}

BS of Company A was used in the experiment, and the physical and chemical properties of the BS are indicated in Table 4. RA of Company D was manufactured in dry condition, and the physical properties of the RA are indicated in Table 5, and its grain distribution is shown in Figure 2. In addition, CA from Oksan, Cheongwon-gun, Chungcheongbuk-do was used to reduce absorption of the BS bricks with $\mathrm{RA}$, and the physical properties and the grain distribution are shown in Table 6 and Figure 2. As EWO, waste oil of Company D was emulsified and used, and the physical and chemical properties are as shown in Table 7.
Table 2. Mixing proportions (series I)

\begin{tabular}{ccccc}
\hline $\begin{array}{c}\text { Mix proportion } \\
\text { (BS : RA })\end{array}$ & W/B & $\begin{array}{c}\text { W } \\
(\%)\end{array}$ & \multicolumn{2}{c}{ Unit weight } \\
$\left(\mathrm{kg} / \mathrm{m}^{3}\right)$ & BS $\left./ \mathrm{m}^{\mathrm{T}}\right)$ & RA \\
\hline \multirow{6}{*}{$1: 10$} & 25 & 54 & 218 & 2176 \\
& 30 & 65 & 215 & 2153 \\
& 35 & 75 & 213 & 2130 \\
& 40 & 84 & 211 & 2108 \\
& 45 & 94 & 208 & 2084 \\
\hline
\end{tabular}

Table 3. Mixing proportions (series II)

\begin{tabular}{|c|c|c|c|c|c|c|c|c|}
\hline \multirow{2}{*}{$\begin{array}{c}\text { Mix } \\
\text { proportion } \\
\text { (BS : RA) }\end{array}$} & \multirow{2}{*}{$\begin{array}{l}\text { W/B } \\
(\%)\end{array}$} & \multirow{2}{*}{$\begin{array}{l}\text { CA } \\
(\%)\end{array}$} & \multirow{2}{*}{$\begin{array}{l}\text { EWO } \\
(\mathrm{C} / \%)\end{array}$} & \multirow{2}{*}{$\underset{\left(\mathrm{kg} / \mathrm{m}^{3}\right)}{W}$} & \multicolumn{4}{|c|}{ Unit weight $\left(\mathrm{kg} / \mathrm{m}^{3}\right)$} \\
\hline & & & & & BS & RA & $\mathrm{CA}$ & EWO \\
\hline \multirow{20}{*}{$1: 10$} & \multirow{20}{*}{35} & \multirow{4}{*}{0} & 0 & 75 & 213 & 2130 & 0 & 0 \\
\hline & & & 1 & 72 & 213 & 2130 & 0 & 2.1 \\
\hline & & & 2 & 70 & 213 & 2130 & 0 & 4.3 \\
\hline & & & 3 & 68 & 213 & 2130 & 0 & 6.4 \\
\hline & & \multirow{4}{*}{10} & 0 & 75 & 214 & 1927 & 214 & 0 \\
\hline & & & 1 & 73 & 214 & 1927 & 214 & 2.1 \\
\hline & & & 2 & 71 & 214 & 1927 & 214 & 4.3 \\
\hline & & & 3 & 69 & 214 & 1927 & 214 & 6.4 \\
\hline & & \multirow{4}{*}{20} & 0 & 75 & 215 & 1723 & 431 & 0 \\
\hline & & & 1 & 73 & 215 & 1723 & 431 & 2.2 \\
\hline & & & 2 & 71 & 215 & 1723 & 431 & 4.3 \\
\hline & & & 3 & 69 & 215 & 1723 & 431 & 6.5 \\
\hline & & \multirow{4}{*}{30} & 0 & 76 & 217 & 1516 & 650 & 0 \\
\hline & & & 1 & 74 & 217 & 1516 & 650 & 2.2 \\
\hline & & & 2 & 71 & 217 & 1516 & 650 & 4.3 \\
\hline & & & 3 & 69 & 217 & 1516 & 650 & 6.5 \\
\hline & & \multirow{4}{*}{40} & 0 & 76 & 218 & 1306 & 871 & 0 \\
\hline & & & 1 & 74 & 218 & 1306 & 871 & 2.2 \\
\hline & & & 2 & 72 & 218 & 1306 & 871 & 4.4 \\
\hline & & & 3 & 70 & 218 & 1306 & 871 & 6.5 \\
\hline
\end{tabular}

\subsection{Experiment method and criteria}

In this study, an electric mixer was used to mix mortar for the brick as stipulated in KS L 5109.

Mortar was filled into a specially designed hydraulic brick making machine, and was pressed to make bricks that would satisfy the target dimensions of $190 \times 57 \times 90 \mathrm{~mm}$ (tolerance $\pm 2 \mathrm{~mm}$ ) as shown in Figure 3. The bricks were steam cured based on KS F 4004 as shown in Figure 4, and compressive strength and absorption were also tested based on KS F 4004 as shown in Figure 5. Compressive strength and absorption criteria for $\mathrm{C}$ type using general aggregate are shown in Table 8, except for Types A and B, light weight bricks[9]. 
Table 4. Physical and chemical properties of BS

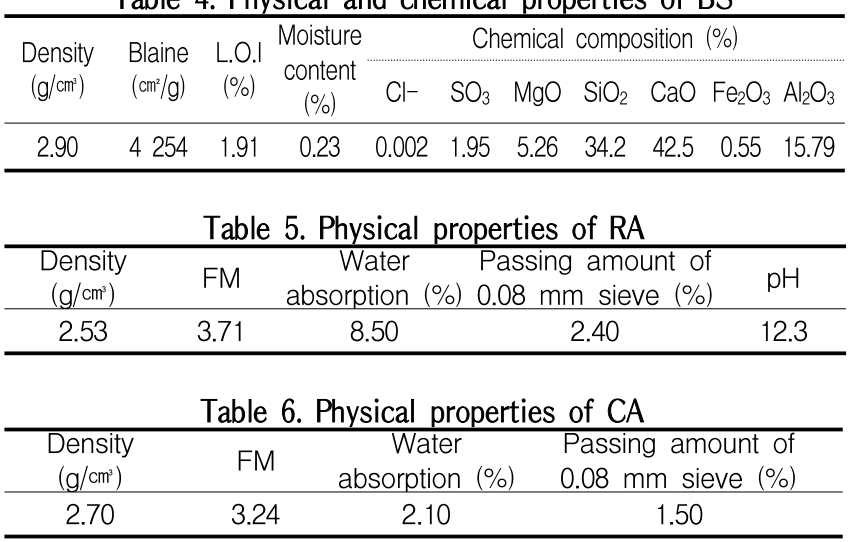

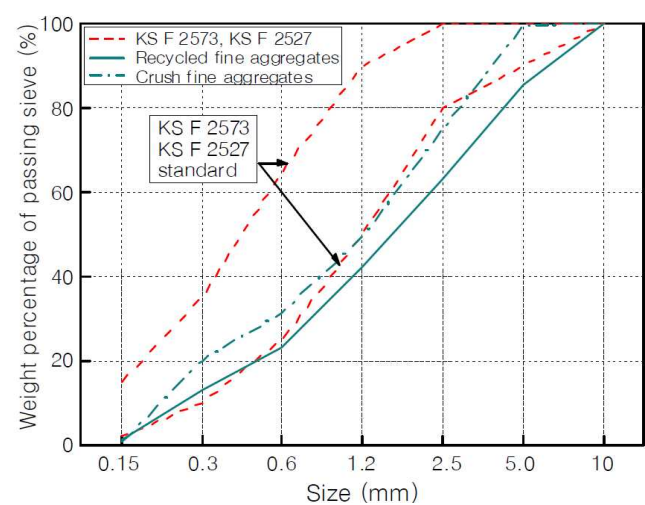

Figure 2. Particle size distribution of RA and CA

Table 7. Physical and chemical properties of EWO

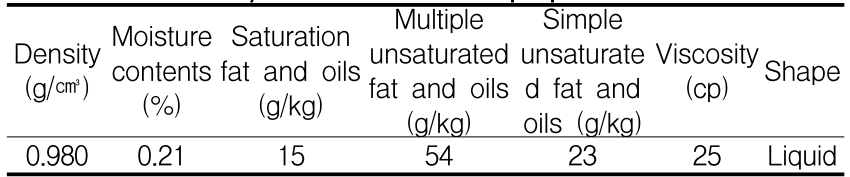

\section{Experiment results and analysis}

\subsection{Quality properties of the lab manufactured bricks}

\subsubsection{Series I : changes of $\mathrm{W} / \mathrm{B}$}

Figure 6 is the compressive strength and absorption by age depending on W/B.

First, as W/B rose up to $35 \% \mathrm{~W} / \mathrm{B}$, the compressive strength was higher at 3 and 7 days. However, the compressive strength dropped again after W/B reached $35 \%$ or higher, which is different from the property of general wet concrete, which develops higher strength as W/B becomes lower. From this, it can be interpreted that the

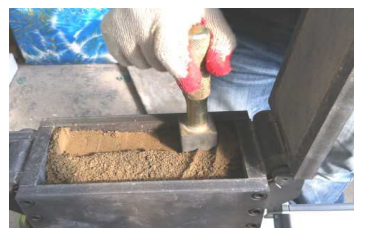

a) Mortar filling

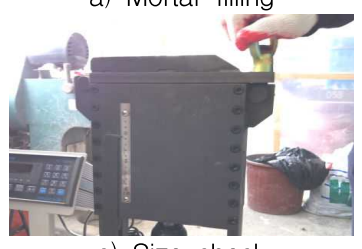

c) Size check

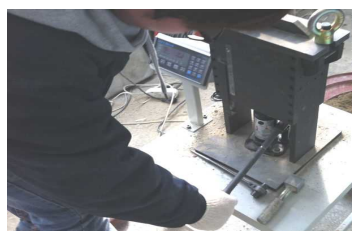

b) Compression molding

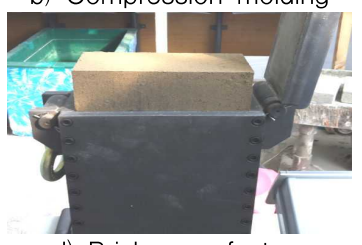

d) Brick manufacture

Figure 3. Process of manufacturing bricks in laboratory

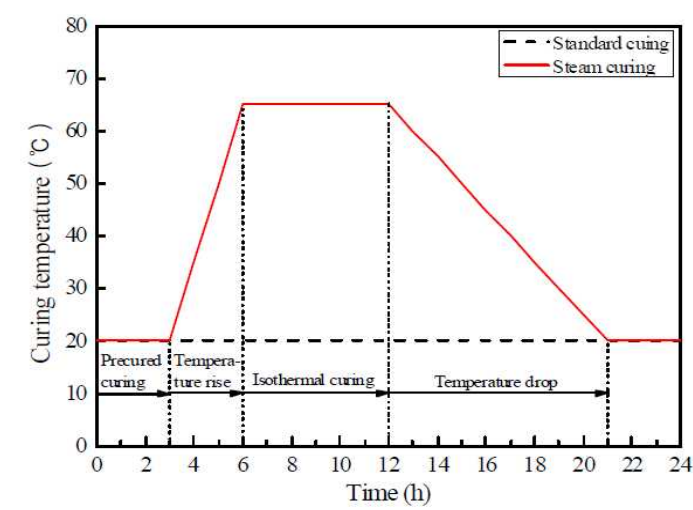

Figure 4. Method of curing bricks

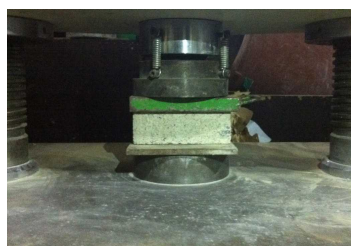

a) Compressive strength

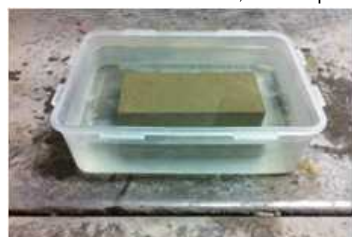

b) Water absorption
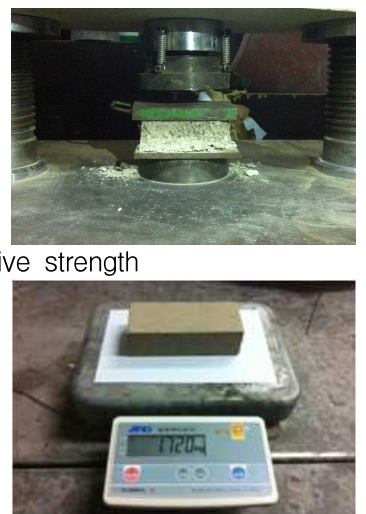

Figure 5. Quality test of bricks

Table 8. KS F 4004 (concrete bricks) standard

\begin{tabular}{cccc}
\hline $\begin{array}{c}\text { KS F 4004 } \\
\text { (Concrete }\end{array}$ Bricks) & $\begin{array}{c}\text { Compressive strength } \\
(\mathrm{MPa})\end{array}$ & Water Absorption (\%) \\
\hline \multirow{2}{*}{ C type } & 1 grade & More than 16 & Less than 7 \\
& 2 grade & More than 8 & Less than 10 \\
\hline
\end{tabular}

different filling level of mortar caused by consistency affected the formation of dry bricks. For dry, lean mix, the optimal consistency should be secured to improve strength development, and 
W/B of $35 \%$ was determined to be optimal. On the other hand, absorption showed the opposite tendency to compressive strength. That is, although the optimal filling was found at W/B of 35\%, and the absorption was the lowest since the internal pores were filled appropriately, all the specimens were observed to fail to meet the criterion, which was an absorption rate of less than $10 \%$, due to high absorption of the RA used as aggregate.

\subsubsection{Series $\square$ Combined replacement of $\mathrm{CA}+\mathrm{EWO}$}

\section{1) Compressive strength}

In Series $\mathbb{I}$, to resolve the absorption problem found in Series I, CA was added to partially replace RA, and EWO was also added to examine the reduction in absorption caused by a saponification reaction within the brick.

First, Figure 7 illustrates compressive strength and strength development at 3 days depending on CA content with EWO content. All specimens were found to satisfactorily meet $8 \mathrm{MPa}$, the strength criterion for Type C 2 Grade.

More specifically, in terms of the compressive strength depending on CA content, the compressive strength was observed to have increased up to CA of $20 \%$ while it decreased again once CA reached 20\% or higher. An appropriate mix proportion of RA and $\mathrm{CA}$ is believed to have led to this result. It was determined that the more CA was replaced, the more appropriate grain distribution was attained, and RA, the low-quality aggregate, was less replaced, which helped initial strength development; however, alkali that could activate potential hydraulic reactivity decreased once CA reached $20 \%$ or higher, and the strength was accordingly found to have a gradual decrease. In addition, in terms of the compressive strength depending on EWO content, it was observed that the more EWO was added, the higher the compressive strength, reaching a peak at

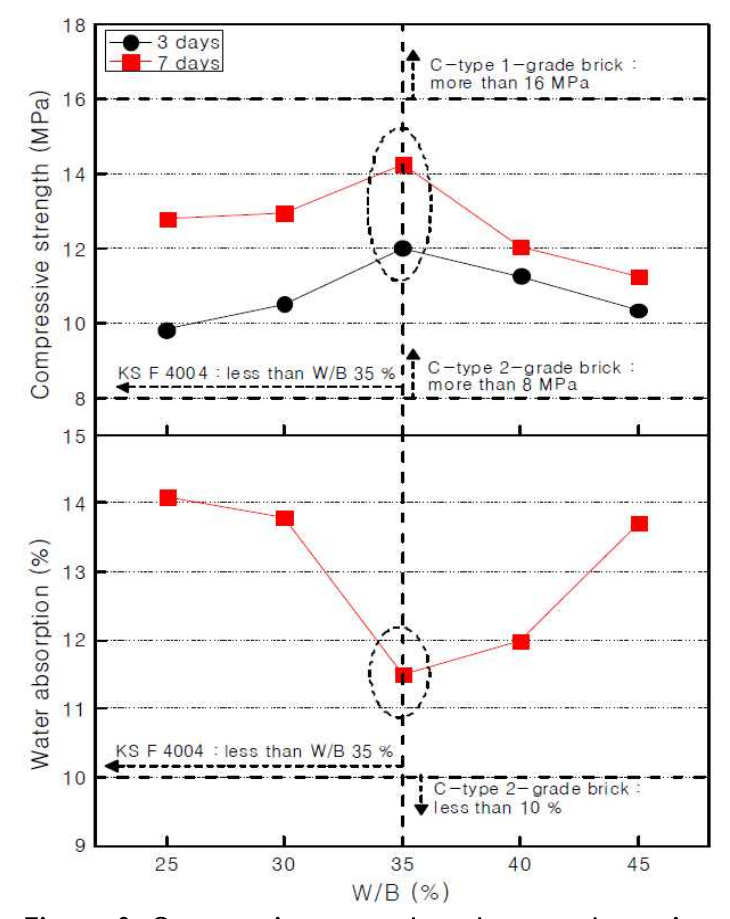

Figure 6. Compressive strength and water absorption depending on W/B with age

CA of $20 \%$ and EOW of $1 \%$, while the compressive strength decreased again from CA of $30 \%$ or higher. It was analyzed that excessive oil content prevented hydration as the EWO content was higher, which led to a decrease in strength[10]. However, the strength did not deteriorate greatly up to EWO of $1 \%$, and rather increased within around 5\% due to an increase in the viscosity of mortar between 0 and $20 \%$ of CA.

Figure 8 is the compressive strength and strength development at 7 days depending on CA content with EWO content.

Overall, unlike the result at 3 days, the compressive strength at 7 days was found to gradually decrease as more CA was replaced, and this is believed to be because the alkali that could trigger the potential hydraulic reactivity of BS was more effective in strength development of the bricks at 7 days with the passage of time rather than the appropriate mix proportion of CA. However, a slight decrease was found within 5\% up to CA of $20 \%$, but decreases of about $10 \%$ and 

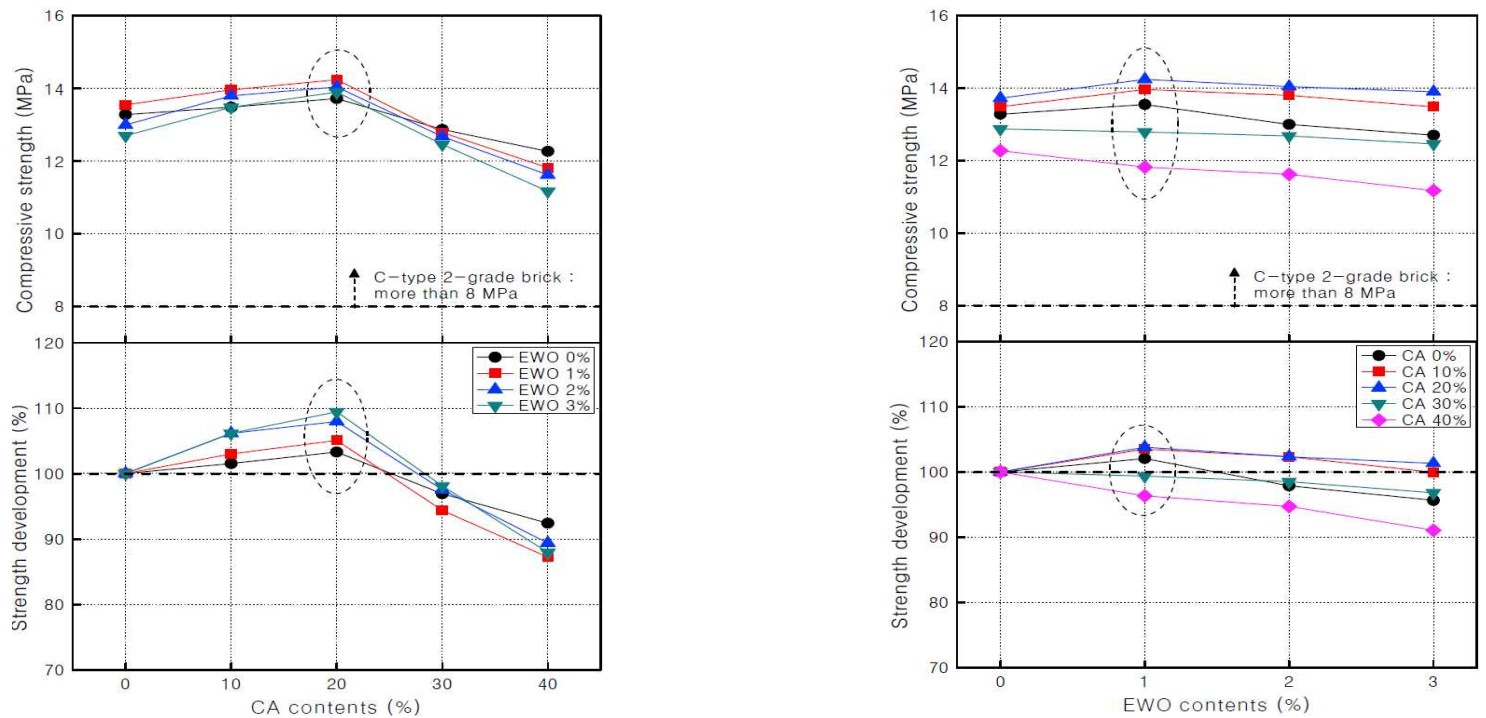

Figure 7. Compressive strength and strength development depending on CA contents with EWO contents (3 days)
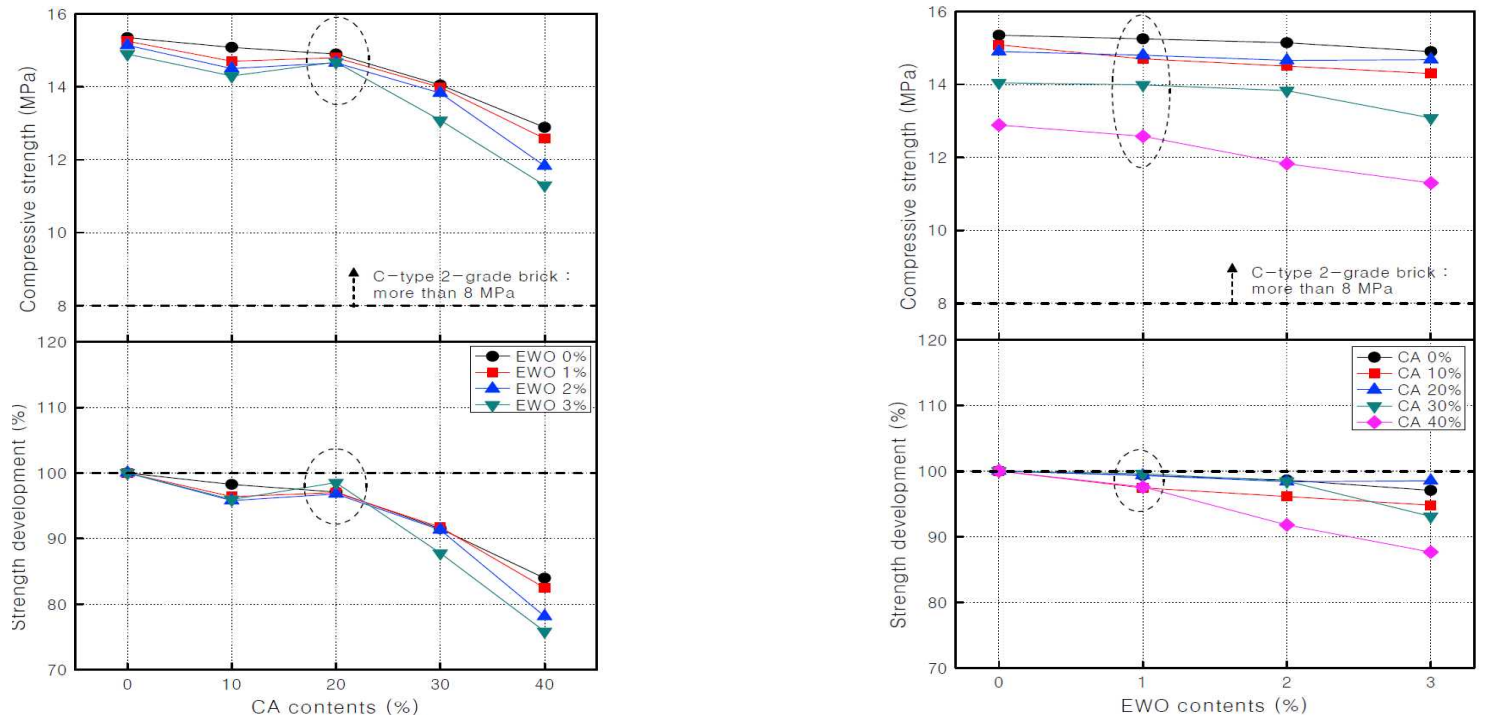

Figure 8. Compressive strength and strength development depending on CA contents with EWO contents (7 days)
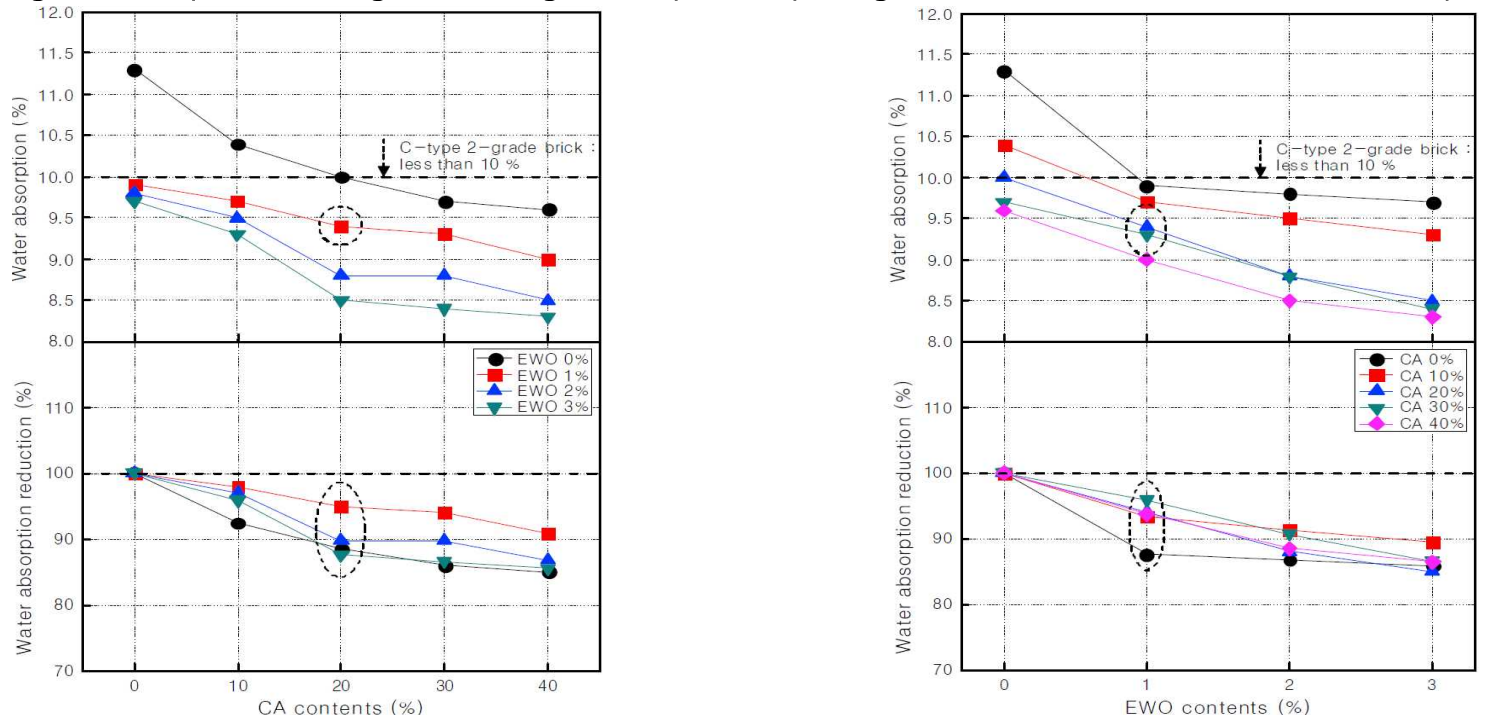

Figure 9. Water absorption and reduction ratio depending on CA contents with EWO contents 
$20 \%$ were observed at CA of $30 \%$ and $40 \%$, respectively. On the other hand, compressive strength depending on EWO content was found have a similar tendency with CA; the more EWO was replaced, the less the compressive strength decreased, but it decreased slightly within 5\% up to EWO of $1 \%$.

2) Absorption

Figure 9 shows the absorption and reduction depending on CA content with EWO content. Overall, the more $\mathrm{CA}$ and EWO were replaced, the more absorption was observed to decrease. At CA of 30\% or higher or EWO of $1 \%$ or higher, the specimens were observed to meet the absorption criterion for $\mathrm{C}$ Type 2 Grade. It is believed that because CA was replaced more, RA with relatively high absorption was replaced less, and the oil ingredient of EWO had an effect of filling capillary pores, resulting in decreased absorption[11]. From the results above, considering the reduction in the compressive strength and absorption caused by the contents of $\mathrm{CA}$ and EWO, the combined replacement of CA of $20 \%$ and EWO of $1 \%$ was found to be the optimal replacement rate to stably satisfy the quality criteria.

\subsection{Application to a brick factory}

The application test was conducted at a brick factory located in Cheongwon-gun, Chungcheongbuk-do, which features a vibrated pressure brick making plant and a steam curing room with a maximum temperature of $50^{\circ} \mathrm{C}$, and produces about 100,000 bricks per day on average.

Figure 10 shows the brick manufacturing process, and Figure 11 is the accredited report by a publicly recognized organization on their test of compressive strength and absorption of bricks, which were tested 5 times at 7 day intervals.

The final bricks produced with the technology showed average compressive strength of $12 \mathrm{MPa}$ and average absorption of $8.4 \%$, lower than the

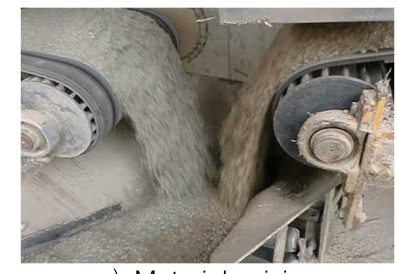

a) Material mixing

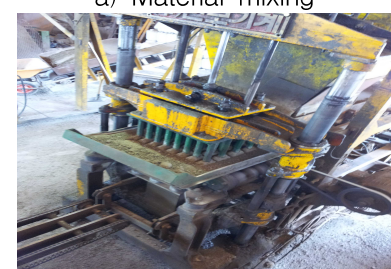

c) Vibration pressure

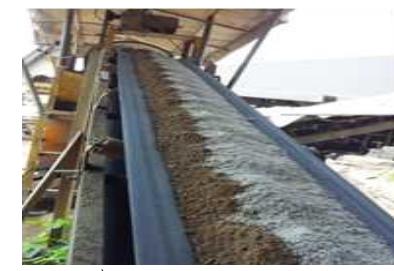

b) Material transport

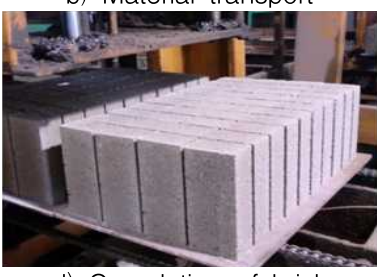

d) Completion of brick

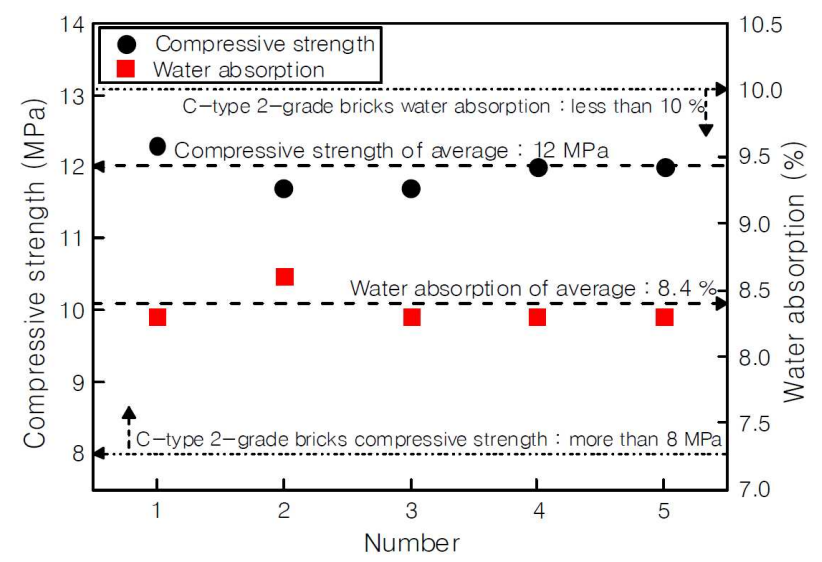

Figure 11. Compressive strength and waterabsorption depending on test certificate of number

Table 9. Construction cost of general cement bricks

\begin{tabular}{|c|c|c|c|c|c|c|}
\hline \multicolumn{2}{|c|}{ Item } & \multirow{2}{*}{$\begin{array}{c}\text { Standard } \\
1 \text { type }\end{array}$} & \multirow{2}{*}{$\begin{array}{l}\text { Unit } \\
\mathrm{Kg}\end{array}$} & \multirow{2}{*}{$\begin{array}{c}\text { Amount } \\
222\end{array}$} & \multirow{2}{*}{ 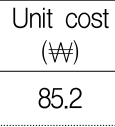 } & \multirow{2}{*}{$\frac{\text { Cost }(\forall)}{18914}$} \\
\hline erial & OPC & & & & & \\
\hline cost & Aggregates & $\begin{array}{l}\text { River } \\
\text { sand }\end{array}$ & $\mathrm{m}^{3}$ & 0.86 & 12000 & 10320 \\
\hline $\begin{array}{c}\text { Labour } \\
\text { cost }\end{array}$ & $\begin{array}{l}\text { General } \\
\text { worker }\end{array}$ & - & People & 1.8 & 75608 & 136094 \\
\hline \multicolumn{2}{|c|}{ Total } & - & - & - & - & 165328 \\
\hline
\end{tabular}

Table 10. Construction cost of RA using the BS bricks

(1 000 sheets)

\begin{tabular}{|c|c|c|c|c|c|c|}
\hline & Item & Standard & Unit & Amount & $\begin{array}{c}\text { Unit cost } \\
(\forall)\end{array}$ & $\begin{array}{c}\text { Cost } \\
(\#)\end{array}$ \\
\hline \multirow{4}{*}{$\begin{array}{c}\text { Material } \\
\text { cost }\end{array}$} & BS & 3 type & $\mathrm{Kg}$ & 218 & 55 & 11990 \\
\hline & \multirow{2}{*}{ Aggregates } & RA & $\mathrm{m}^{3}$ & 0.69 & 5800 & 4002 \\
\hline & & CA & $\mathrm{m}^{3}$ & 0.16 & 7250 & 1160 \\
\hline & Agent & EWO & $\mathrm{Kg}$ & 2.20 & 2200 & 4840 \\
\hline $\begin{array}{c}\text { Labour } \\
\text { cost }\end{array}$ & $\begin{array}{l}\text { General } \\
\text { worker }\end{array}$ & - & People & 1.8 & 75608 & 136094 \\
\hline \multicolumn{2}{|r|}{ Total } & - & - & - & - & 158086 \\
\hline
\end{tabular}


results in the laboratory mock-up test, but still satisfying KS F 4004: Brick Quality Criteria for C Type 2 Grade.

Tables 9 and 10 indicate the cost breakdown of manufacturing general bricks and 1000 BS bricks with RA in a unit, respectively. The cost breakdown was made by converting the mix design result based on cement brick manufacturer cost in the 2011 first half standard of estimate and basic data provided by Korea Price Research Center, which included minor transport, curing and surcharge.

From the calculation results obtained based on quantity and price, KRW165,328 was required for general cement bricks, while KRW158,086 was required for the bricks designed in this research. It was confirmed that KRW7,242 was required to manufacture a unit quantity of 1000 bricks, a 5\% decrease in manufacture cost.

\section{Conclusion}

In this study, the method of manufacturing zero cement bricks with BS and RA was examined in a series of processes from the laboratory mock-up test to the application to a factory, and the findings are as follows:

1) In terms of the compressive strength depending on $\mathrm{W} / \mathrm{B}$, it was highest at W/B of $35 \%$, but decreased when W/B was lower or higher than $35 \%$. Absorption showed an opposite tendency to compressive strength, and was lowest at W/B of 35\%. However, the bricks failed to meet KS F 4004: Absorption Criteria for C Type 2 Grade due to the high absorption of RA.

2) In terms of the compressive strength at 3 days depending on combined replacement of CA and EWO, it was highest at CA of 20\%, and decreased after that. As EWO was mixed more, the strength was highest at CA of $20 \%$ and EWO of $1 \%$, but decreased after that as more EWO was mixed.

3) In terms of the compressive strength at 7 days depending on combined replacement of $\mathrm{CA}$ and EWO, it was shown to be decreasing as CA and EWO were mixed more. There was about a $5 \%$ decrease in strength at $\mathrm{CA}$ of $20 \%$ and EWO of $1 \%$.

4) Absorption was shown to decrease as CA and EWO were mixed more. Taking the decrease in compressive strength and reduction in absorption into account, the bricks met KS Quality Standard at CA of $20 \%$ and EWO of $1 \%$.

5) From the application to a factory, the average compressive strength and the average absorption stood at $12 \mathrm{MPa}$ and 8.4\%, respectively, through 5 tests at 7 day intervals, which were lower than those found in the laboratory mock-up test, but they met the KS Criteria stably. In addition, when using RA and BS, the manufacturing cost of zero cement bricks in a unit of 1000 pieces was shown to be about 5\% lower than that of general cement bricks.

\section{References}

1. Lee JK. New Material Sufficing Modern Social Demands -Geopolymer-. Journal of the Korea Institute of Building Construction. 2010 December;10(6):27-31.

2. Yang GH, Song GK. The Properties and Applications of Alkali-Activated Concrete with No Cement, Journal of the Korea Concrete Institute. 2007 March;19(2):42-8.

3. Yang GH, Sim JI, Song JK, Lee JH. Material Properties of Slag-Based Alkali-Activated Concrete Brick-Masonry. Journal of Architectural Institute of Korea. 2011 January;27(1):119-26.

4. Han JS. An Improvement Method on the Using Problem of the Ground Granulate Blast-Furnace Slag as a Concrete 
Admixture in Ready-Mixed Concrete Plant. Journal of Architectural Institute of Korea. 2003 March;15(2):6-7.

5. Ministry of Land (KR). [Recycled Aggregates Quality Standard]. Gwa-cheon (Korea): Ministry of Land; 2009. p. 82. Korean.

6. Lee DH. Problem and Countermeasure of Recycled Aggregates for Concrete. Korean National Housing Corporation. Housing and Urban. 2004 August;83:29-35.

7. Park KT, Son SK, Han CG. Quality Properties of Zero Cement Blast Furnace Slag Mortar Using the Recycled Fine Aggregates Depending on Mixing Factors. Journal of Architectural Institute of Korea. 2010 September;5(3):69-76.

8. Park KT, Han CG, Kim DG. Effect of Fine Particle Cement on the Quality of Recycled Fine Aggregates Mortar Using the Blast Furnace Slag Powder. Journal of Architectural Institute of Korea. 2012 September;28(9):131-8.

9. Agency for Technology and Standards (KR). KS F 4004 [Concrete Bricks]. Gwa-cheon (Korea): Korean Standards Information Center; 2011. Korean.

10. Han MC, Song RF. Autogenous Shrinkage and Fundamental Properties of the High Strength Mortar Containing Waste Vegetable Oil. Journal of Korea Recycled Construction Resource Institute. 2010 March;5(1):97-102.

11. Han MC, Kim TC. Autogenous Shrinkage of the High Strength Concrete Using Emulsified Waste Cooking Oil. Journal of Architectural Institute of Korea. 2012 September;28(9):139-46. 